\title{
ЗОоЛОГИЯ
}

УДК 57.065:577.29

doi: $10.17223 / 19988591 / 34 / 7$

\author{
Anastasia V. Simakova ${ }^{1}$, Tamara F. Pankova ${ }^{1}$, \\ Irma V. Issi ${ }^{2}$, Yulia V. Andreeva ${ }^{1}$ \\ ${ }^{1}$ Tomsk State University, Tomsk, Russian Federation \\ ${ }^{2}$ All-Russian Institute of Plant Protection, St. Petersburg-Pushkin, Russian Federation
}

\section{Ecological aspects of microsporidia parasitizing in natural populations of the Aedes (Diptera: Culicidae) blood-suking mosquitoes in Western Siberia}

\author{
Funding: This work was partially supported by "DI Mendeleev Science Fund \\ of Tomsk State University".
}

\begin{abstract}
We examined microsporidia (1976-2014) in natural populations of blood-sucking Aedes mosquitoes of Western Siberia with the focus on their biodiversity and ecology. In total, we recorded 31 species of Culicidae family mosquitoes in Western Siberia; 22 species of them belong to the univoltine genus Aedes, producing one generation per year (spring). As it has been shown, microsporidians infect 13 mosquito species. In this study, we isolated 26 microsporidian species representing five genera (Amblyospora, Andreanna, Dimeiospora, Novothelohania, and Trichoctosporea) from mosquitoes; of them, the Amblyospora species were the most abundant. The majority of species display a high level of host specificity. Microsporidians are found in all types of aquatic habitats; however, the highest diversity of parasites was observed in mainland temporary ponds. During the period of study, the prevalence rates of microsporidians infecting Aedes mosquitoes varied from 0.05 to $100 \%$, with the maximal parasite prevalence during mass mosquito pupation and imago emergence (mid-May - beginning of June). Low parasite loads (0.05-6.5\%) are characteristic of the last 20 years.
\end{abstract}

Key words: Aedes; Amblyospora; microsporidia; blood-sucking mosquitoes; ecology; epizootiology; host specificity.

\section{Introduction}

The intracellular parasites of a Microsporidia type are abundant in the bloodsucking mosquitoes of the family Culicidae. These parasites are the most diverse in the mosquitoes belonging to the genus Aedes Meigen. Currently, 14 genera and over 100 species of microsporidians in these mosquitoes have been described, being the largest number as compared with other mosquito genera [1-6]. Representatives of some genera of these parasites have complex mono-, di-, tri, and tetramorphic life cycles with changing hosts. 
Microsporidians are observed in the populations of blood-sucking mosquitoes at rather low abundance but are able to cause the disease outbreaks affecting a large number of individuals in the population. The infection rate of natural populations varies depending on the specific features of the parasite-host system itself, particular biotope, season and year.

The insight into epizootics in natural populations of blood-sucking mosquitoes is of great practical importance, making it possible to assess the role of the disease agent in the control of mosquito populations and giving the background for elaboration of the corresponding control methods. Many mosquito species of the genus Aedes are vectors of dangerous diseases. Correspondingly, the study of antagonistic interactions between microsporidians and various pathogens of medicinal and veterinarian importance that stop or slow down their development in the female mosquitoes invaded by microsporidians is also of great practical value.

This work summarizes the long-term studies (1976-2014) of the species composition of Microsporidia, their host specificity, as well as seasonal and long-term rates of microsporidian infection of the Aedes mosquitoes in Western Siberia.

\section{Materials and methods}

Microsporidians from the univoltine Aedes mosquitoes were studied in Western Siberia (Russia) during 1976-2014. Western Siberia has an area of about 2.5 million $\mathrm{km}$, spanning from north to south for almost $3000 \mathrm{~km}$.

The studies were performed in the taiga landscape zone (middle and southern subzones, Tomsk oblast), forest-steppe zone (aspen-birch forests and foreststeppe of Novosibirsk and Kemerovo oblasts), and the Salair mountain area near Kopna Mountain (altitude, 509 m, Kemerovo oblast).

The work over this period comprised stationary observations and surveys at over 200 water bodies of various types (mainland, floodplain, constant, temporary, open, closed, natural, artificial, formed by snow melting, meadow and forest bogs, as well as sphagnum, raised and reed bogs). The long-term annual microsporidian infection prevalence in mosquitoes was monitored in several model water bodies.

The mosquito larvae were harvested according to Pavlovskii (1935) [7]. The samples in water bodies with a circumference up to $200 \mathrm{~m}$ were taken every $10 \mathrm{~m}$ with a dip net. In water bodies with a shore length of 200-1000 m, sites differing in their vegetation and illumination were examined. The surveys were performed every 5 days over the entire season. Concurrently, copepods were collected in water habitats.

The larvae of blood-sucking mosquitoes were identified according to their morphological characters [8] and with the help of molecular genetic methods [5].

The collected larvae and copepods were examined in the laboratory against a dark background using an "MBS-10" (Lytkarino Optical Glass Factory, Russia) or an "MSP-1" (Leningrad Optical Mechanical Association, Russia) microscope $(20 \times)$ to detect the individuals infected with microsporidians. 
The species composition of Microsporidia was studied using standard procedures of light and electron microscopies as well as molecular genetic tools [4, 9].

\section{Results}

1.1. Species compositions of parasites and insect hosts. In total, 45 species of Aedes mosquitoes have been recorded in Siberia [10]. A systematic and intensive study of the blood-sucking mosquito fauna and ecology in the Tomsk Ob River area commenced in the 1970s-1980s [11-14]. The list of blood-sucking mosquitoes of that time comprised 38 species and eight subspecies belonging to five genera (Anopheles Meigen, Aedes, Culex L., Culiseta Felt, and Mansonia Dyar), the majority of species (25 species) being the members of the genus Aedes [14].

The data of the last decade demonstrate that the taiga zone (Tomsk oblast) houses 31 mosquito species of the family Culicidae; of them, 22 species belong to the univoltine genus Aedes, which produced one generation a year and develop during the spring season [15]. The forest-steppe zone of Western Siberia (Novosibirsk oblast) houses 20 species of the Aedes mosquitoes [16], most of which are ubiquitous in Western Siberia.

Microsporidians were detected in 13 Aedes species (Table 1).

Table 1

Microsporidian species from univoltine Aedes mosquitoes in Western Siberia

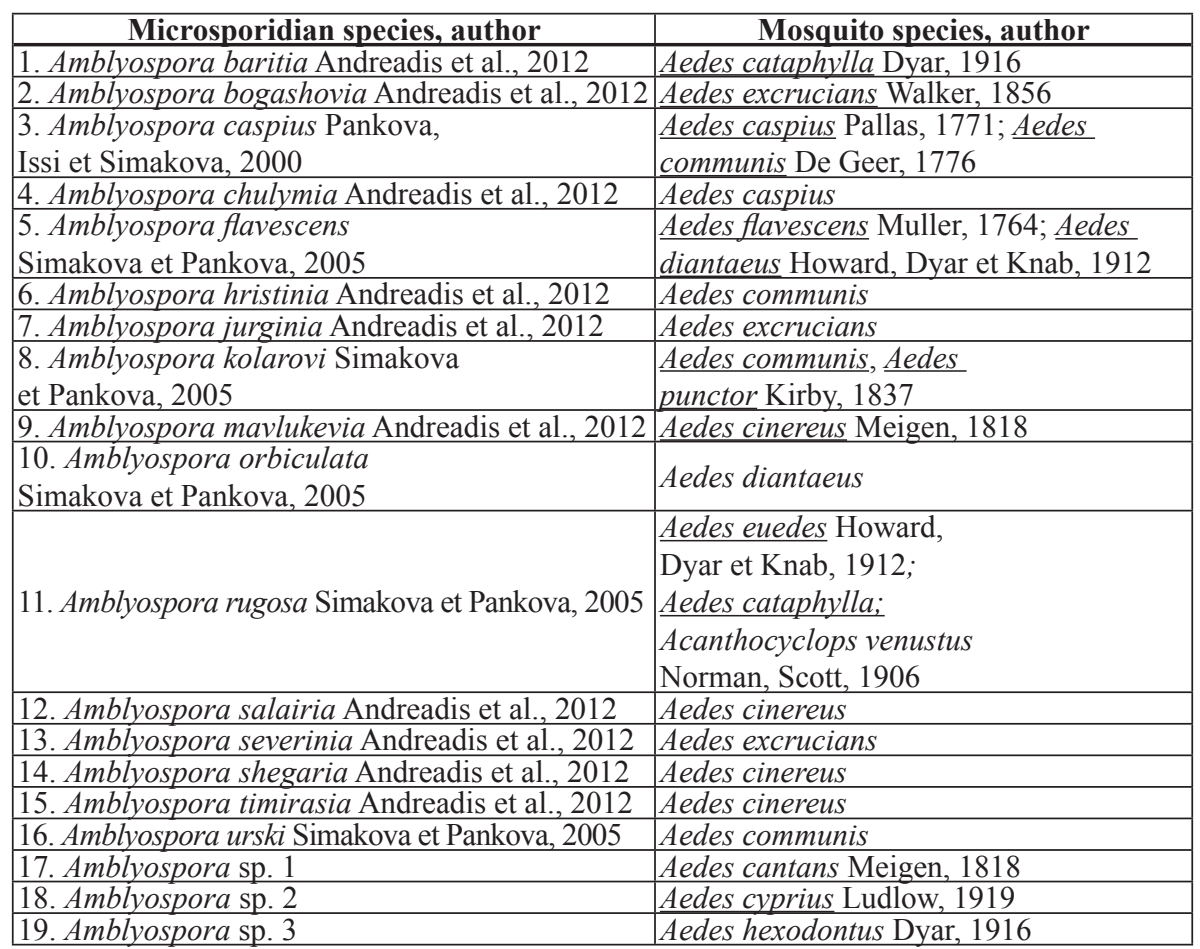


T a ble 1 (end)

\begin{tabular}{|l|l|}
\hline \multicolumn{1}{|c|}{ Microsporidian species, author } & \multicolumn{1}{c|}{ Mosquito species, author } \\
\hline 20. Amblyospora sp. 4 & Aedes intrudens Dyar, 1906 \\
\hline 21. Amblyospora sp. 5 & Aedes leucomelas Meigen, 1804 \\
\hline $\begin{array}{l}\text { 22. Andreanna caspii Simakova, } \\
\text { Vossbrinck et Andreadis, 2008 }\end{array}$ & Aedes caspius \\
\hline $\begin{array}{l}\text { 23. Dimeiospora palustris Simakova, } \\
\text { Pankova et Issi 2003 }\end{array}$ & Aedes punctor \\
\hline $\begin{array}{l}\text { 24. Novothelohania ovalae Andreadis et al., 2012 } \\
\text { 25. Trichoctosporea colorata } \\
\text { Simakova et Pankova, 2004 }\end{array}$ & \begin{tabular}{l} 
Aedes caspius \\
\hline Aedes euedes, Aedes punctor,
\end{tabular} \\
\hline 26. Trichoctosporea pygopellita Larsson, 1994 & $\begin{array}{l}\text { Aedes flavescens; } \text { Aedes } \\
\text { excrucians; Aedes cyprius }\end{array}$ \\
$\begin{array}{l}\text { Ludlow, 1919; Acanthocyclops } \\
\text { reduculus } \text { Chappuis, } 1925\end{array}$ \\
\hline
\end{tabular}

Note: The mosquito species infected with several microsporidian species are underlined.

In total, 26 parasite species belonging to five genera were isolated from mosquitoes, namely, the genera Amblyospora Hazard et Oldacre, 1975; Andreanna Simakova et al., 2008; Dimeiospora Simakova, Pankova et Issi, 2003; Novothelohania Andreadis et al, 2012 and Trichoctosporea Larsson, 1994 (Fig. 1). Note that 20 microsporidian species and three genera were regarded as new for science (Table 1), [4, 5, 17-20]; and five microsporidian specimens were not identified to the level of species. The largest number of species belongs to the genus Amblyospora (16 identified and five unidentified species).

1.2. Host specificity. Microsporidians were recorded in mass (Aedes cinereus, Ae. communis, Ae. diantaeus, and Ae. punctor) and abundant (Ae. excrucians) mosquito species as well as in common (Ae. cantans, Ae. flavescens, and Ae. cyprius) and low-abundance species (Ae. caspius, Ae. cataphylla, Ae. euedes, Ae. leucomelas, and Ae. hexodontus). Many mosquito species carry several microsporidian species as parasites, namely, seven species were recorded in Ae. excrucians, five in Ae. cinereus, three in Ae. caspius (three species), and two in Ae. diantaeus (Table 1) $[5,17,19,20]$.

Our studies have shown that the 15 microsporidian species detected in the $\mathrm{Ae}$ des mosquitoes infect only one host mosquito species each and six microsporidian species have several insect host species, namely, Amblyospora caspius, A. flavescens, A. kolarovi, A. rugosa, Trichoctosporea colorata, and T. pygopellita (Table 1) $[17,19,20]$.

\subsection{The microsporidian infection rate in mosquitoes in different biotopes.} According to our long-term studies, the mosquito larvae are most abundant in small mainland temporary ponds of natural (bogginess and depressions filled with spring waters) and artificial (pits and roadside ditches) origins. The abundance of larvae in these water bodies varies in the range of 2-57 individuals $/ \mathrm{m}^{2}$ and 4-50 individuals $/ \mathrm{m}^{2}$ in the floodplain water bodies versus a considerably lower abundance, 7-18 individuals $/ \mathrm{m}^{2}$, in the constant mainland water bodies. 

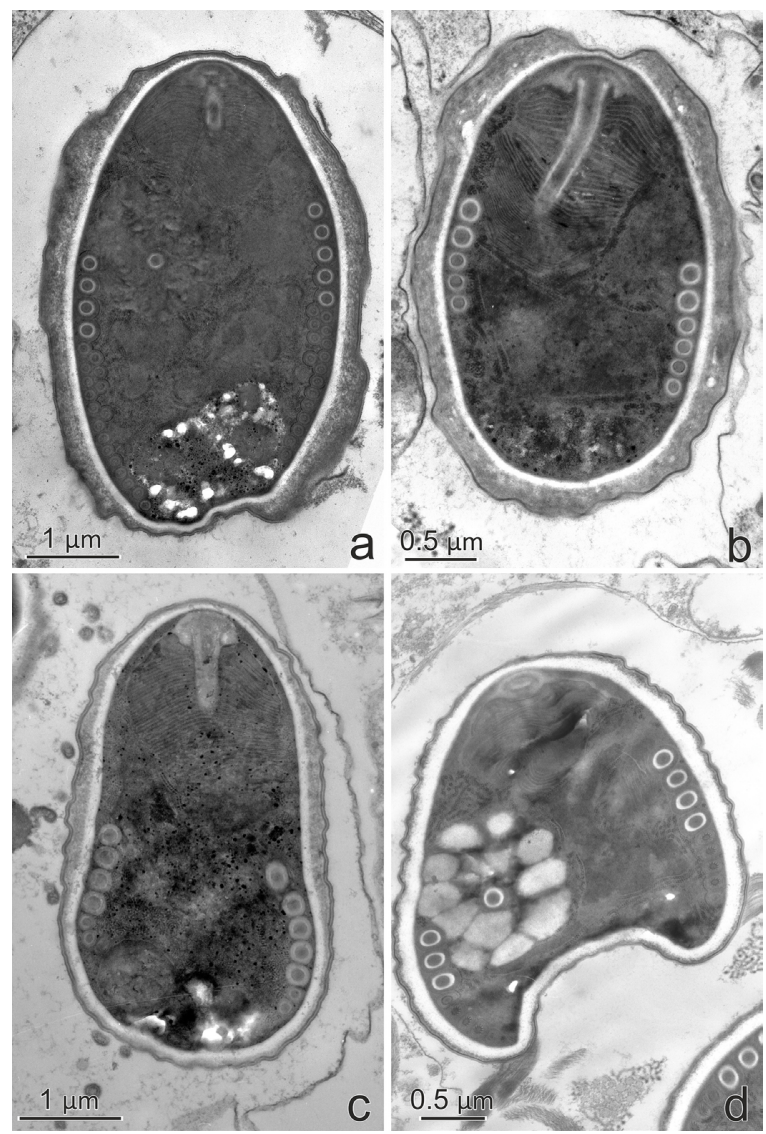

Fig. 1. Ultrastructural morphology of the meiospores of the microsporidian genera isolated from Aedes mosquitoes:

a - Amblyospora, b - Andreanna, c - Novothelohania, d - Trichoctosporea (Photos are taken by AV Simakova, AA Miller authors)

Microsporidians are present in all types of water bodies in Western Siberia, being the most diverse (22 species) in the mainland temporary ponds (forest and meadow bogginess after snow melting, sphagnum bogs, and so on), since characteristic of these habitats is the mass emergence of Aedes mosquitoes, the major host for these parasites.

The study of distribution of the Amblyospora species over the territory of Western Siberia has shown that the species A. kolarovi, A. rugosa, and A. severinia, parasitizing a single or several host species and inhabiting various types of water bodies, have a wide distribution range. Characteristic of the remaining species is a local distribution.

1.4. Seasonal distribution of the Amblyospora microsporidians in natural Aedes mosquito populations. The Aedes larvae displaying evident signs of mi- 
crosporidian infection were recorded from the first molts to the third-fourth instar (first 5-day period in May) and to the end of the larval season (late May-early June). An increase in the infection extensity was proportional to the increase in the number of larvae and pupae. By the end of May, when the healthy larvae massively pupate and imagoes massively emerge, the rate of infected larvae increases, while the share of the fourth instar larvae decreases. This is explainable by a delay in the development of infected individuals and their accumulation in water bodies.

The data of annual studies at the raised sphagnum bog near the village of Kolarovo (56 $\left.199^{\prime} 52.19^{\prime \prime} \mathrm{N}, 84^{\circ} 58^{\prime} 18.74^{\prime \prime} \mathrm{E}\right)$ in 1979-1984 demonstrate that the first larvae of the fourth instar appear during the first 5-day period of May concurrently with the first recorded infected larvae. The infection rate in mosquito population at that time is low (not exceeding $1 \%$ ). Then the rate of healthy larvae decreases, whereas the number of infected larvae grows. In the fifth 5-day period of May, the number of larvae drastically decreases because of mass pupation of healthy larvae and emergence of imagoes, while the number of infected individuals in the population drastically increases (Fig. 2).

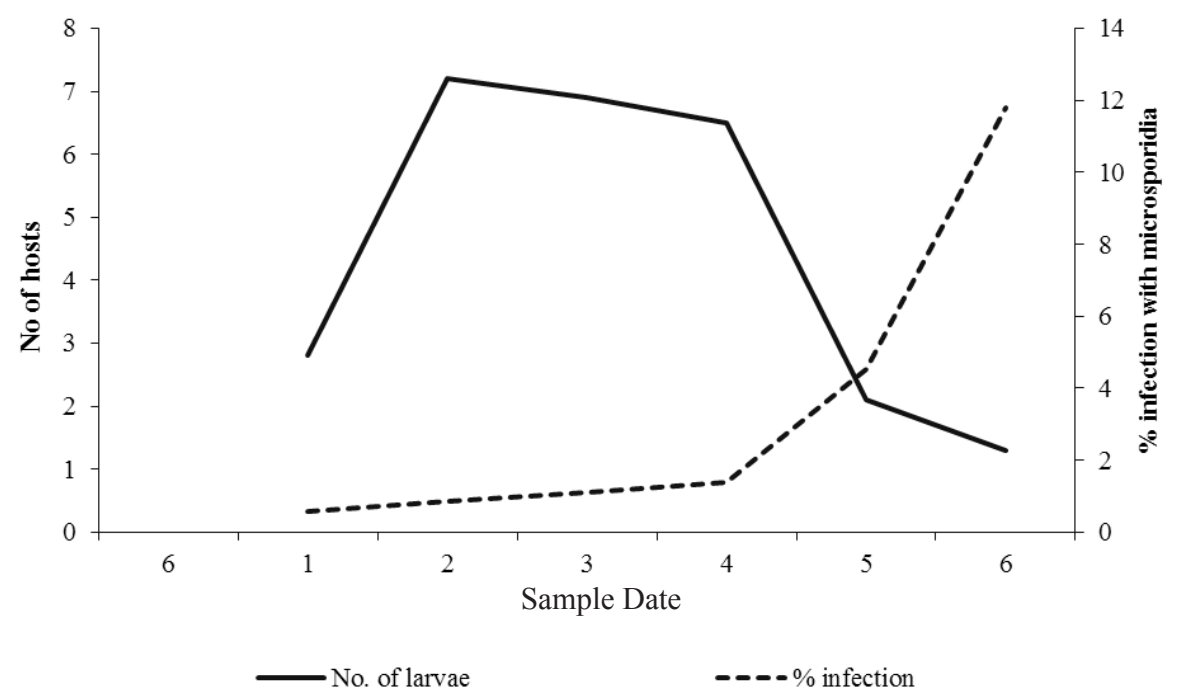

Fig. 2. Seasonal abundance of Aedes mosquitoes and prevalence of Amblyospora infection: 1 - Abundance of larvae, 2 - Microsporidian prevalence rates.

\subsection{Long-term data on the rate of microsporidian infection in natural} mosquito populations. The annual monitoring of the microsporidian infection prevalence in Aedes mosquitoes in 1976-2014 in the raised sphagnum bog near the village of Kolarovo demonstrated the following patterns. A large focus of microsporidian infection was observed in 1976: almost $100 \%$ of the larvae died as a result of this outbreak. In 1977-1978, a decrease in the infection rate was observed followed by an increase in 1979-1984 (Fig. 3). 


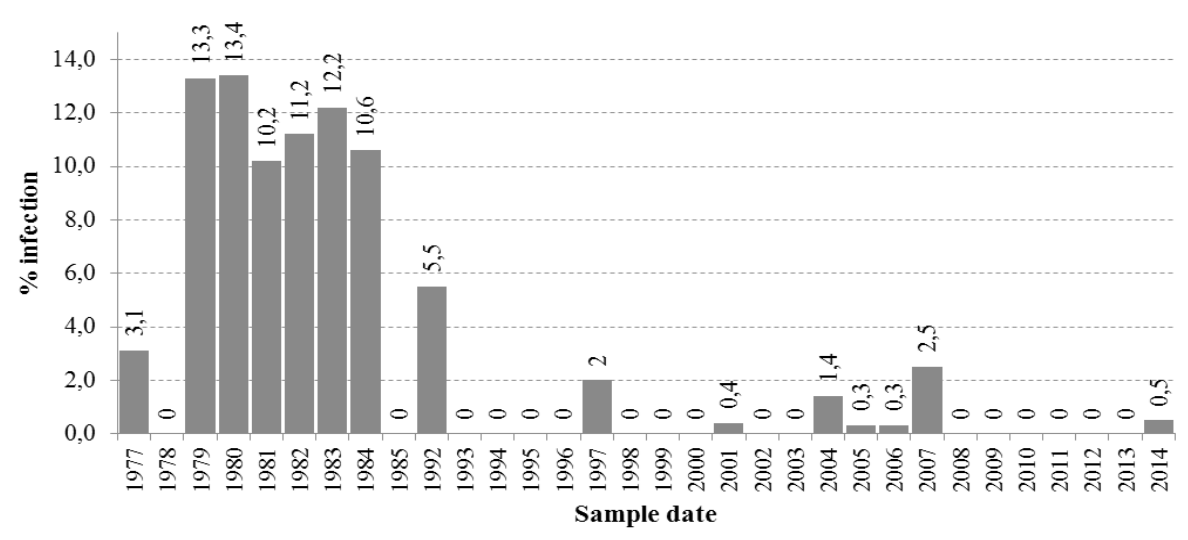

Fig. 3. Yearly prevalence of microsporidian infections in the Aedes larval populations in the raised sphagnum bog near the village of Kolarovo, Tomsk raion, Tomsk oblast, Russia, 1977-2014

In the subsequent years, no outbreaks of the disease were observed and the infection prevalence in mosquito larvae in this bog did not exceed tenths of a percent (Fig. 3). The Ae. punctor and Ae. communis were predominantly infected; Ae. euedes, Ae. flavescens, Ae. diantaeus, and Ae. cinereus were infected to a lesser degree; and the Ae. cantans, Ae. cataphylla, Ae. excrucians, and Ae. intrudens larvae, rarely. The main parasitic species were Amblyospora flavescens, A. kazankia, A. kolarovi, and A. orbiculata.

The observations of the Aedes mosquito larvae in temporary ponds formed by melting snow (Universitetskaya Roshcha of Tomsk State University, Tomsk; $56^{\circ} 28^{\prime} 12.78^{\prime \prime} \mathrm{N}, 84^{\circ} 56^{\prime} 59.98^{\prime \prime}$ E) succeeded in detecting a large focus of microsporidian infection in 1994. By the end of May, the infection rate of the fourth instar larvae reached $40 \%$. The Ae. caspius and Ae. communis mosquitoes were similarly infected with the Amblyospora caspius. The larval infection rate in this water body in 1995 amounted to $19 \%$; in 1996 , to only $1.9 \%$; and no infected larvae were recorded during several subsequent years. A few infected larvae were found only in 2005 (infection extensity, 0.05\%). In 2006-2014, any infected larvae were undetectable.

In 2002, a focus of the microsporidian infection was recorded in a constant mainland pond in the city of Tomsk $\left(56^{\circ} 30^{\prime} 6.09^{\prime \prime} \mathrm{N}, 85^{\circ} 2^{\prime} 0.23^{\prime \prime} \mathrm{E}\right)$; the larval infection rate there during mass pupation reached $25 \%$. The Ae. excrucians and Ae. flavescens larvae were mainly infected and the Ae. euedes and Ae. punctor larvae, to a lesser degree. The parasites were identified only to the level of genus and belonged to Amblyospora.

No mass epizootics of microsporidian infection in the larvae of univoltine Aedes mosquitoes were recorded in the remaining water bodies of the examined territory. The infection extensity in the natural mosquito populations was at a stably low level, amounting to $0.05-6.5 \%$ in different water bodies. The infection 
rate observed in the fourth instar larvae during the second week of May was 0.05$0.4 \%$ elevating to $1.2-6.5 \%$ by the end of May - beginning of June.

Thus, the long-term monitoring of the microsporidian infection prevalence in Aedes mosquito larvae in natural populations of Western Siberia demonstrates a significant variation in infection extensity from 0.05 to $100 \%$.

Summing up the results, we may state that the microsporidians - parasites of the univoltine Aedes mosquitoes - mainly cause enzootics rather than epizootics (which are very rare) in the natural populations of blood-sucking mosquitoes in Western Siberia.

\subsection{The specific features in the life cycles of Amblyospora and Trichoc-} tosporea microsporidians. The microsporidians belonging to the genera Amblyospora and Trichoctosporea are polymorphic and heteroxenous parasites. The sequencing data for the small ribosome subunit rRNA of the microsporidians isolated from mosquitoes and copepods as well as numerous ecological observations suggest that the Amblyospora and Trichoctosporea microsporidians in Western Siberia have complex trimorphic life cycles with the univoltine Aedes mosquitoes as the definitive host and the Acanthocyclops (Norman et Scott) copepods as a potential intermediate host [21].

Our study [21] of the life cycles of Amblyospora microsporidians completely confirmed the data by other researchers for several other species of the same genus [3, 22-31]. In Western Siberia, the copepods inhabiting temporary water bodies, which were infected by meiospores from mosquito larvae, emerge from diapause by the end of April. The parasites there start to develop and form spores. Copepods die at the beginning of May (the infection extensity in natural mosquito populations is $0.01-2.5 \%$ ) [32]. At the same time (early May), the larvae of univoltine Aedes mosquitoes emerge, are orally infected with the copepod spores and develop to imagoes. In the female mosquitoes, the parasites undergo sexual process and give diplokaryotic spores for transovarial transmission. The females lay infected eggs over the summer. The mosquito eggs overwinter with the microsporidian meronts.

Next spring, microsporidians form monokaryotic meiospores in the infected male fourth instar larvae; such mosquito larvae die. The healthy larvae pupate and emerge as imagoes (end of May-beginning of June). The meiospores are invasive for copepods, which are still abundant at that time. Copepods are orally infected with meiospores and enter their diapause, carrying meronts of the parasite, to remain dormant until next spring, since the water bodies they inhabit dry up.

Thus, the life cycle of the Amblyospora and Trichoctosporea parasites is not only synchronized with the life cycles of both hosts (mosquitoes and copepods), but is also adapted to specific ecological features of the region. This allows microsporidians both to exist in populations for rather a long time and to avoid causing epizootics despite their high abundance.

Consequently, a complex life cycle of the Amblyospora microsporidians, which guarantee a long-term existence of this host-parasite system, can be regarded as 
an adaptation providing the preservation of both the parasite and its host. A large number of adaptations of these microsporidians to the development in mosquitoes as well as their uniquely complex life cycles suggest long-term interactions between the parasite and the host established during their coevolution.

\section{Discussion}

Intensive research into the microsporidians of blood-sucking mosquitoes, which started in the second half of the last century in all developed countries, was driven by the search for highly pathogenic microorganisms with the potential to control the insects of medical and veterinary importance.

The earlier studies and identification of the octospores microsporidians parasitizing various mosquito species suggested a wide specificity of many species indistinguishable according to their taxonomic characters at the level of light microscopy. However, involvement of electron microscopy data on the developmental stages and mature spores of microsporidians confirmed that in the majority of cases that the microsporidians of blood-sucking mosquitoes displayed narrow host specificity. It was concurrently found out that the microsporidians with a narrow specificity for their definitive host were able to utilize several crustacean species as an intermediate host [30].

We have shown that most microsporidian species from the univoltine Aedes mosquitoes display narrow host specificity; however, several microsporidian species can parasitize different mosquito individuals of the same host species [4, 5].

Numerous long-term epizootological studies in Russia, Karelia, Ukraine, Uzbekistan and Azerbaijan, as well as in various regions of North and South Americas [22, 33-46] have demonstrated that microsporidians cause enzootics in larval population of the univoltine and polyvoltine Aedes species with a stably low infection rate (several tenths of a percent to 10-20\%) during all examined years, whereas epizootics are a very rare event. As has been observed, the infection extensity in natural copepod populations is somewhat higher as compared with the mosquito larval populations.

In Western Siberia, the Aedes mosquitoes infected by microsporidians are recorded from the very emergence of the fourth instar larvae and to the end of the larval season (early May to mid-June), i.e., to the emergence of adult mosquitoes. Outbreaks of microsporidian infections were recorded in the 1970s-1980s; at that time, the microsporidian infection prevalence in natural populations of univoltine Aedes larvae reached $100 \%$. Most likely, this is explainable by the fact that the larval infection is assessed when the healthy larva undergo mass pupation. Low microsporidian prevalence, varying from 0.05 to $6.5 \%$ in different water bodies, is observed in the natural populations of blood-sucking mosquitoes during the last two decades. The major mechanism underlying stabilization of the parasitic system of Amblyospora microsporidians-blood-sucking Aedes mosquitoes is a complex life cycle of the parasite, which is synchronized with the life cycles of its hosts, blood-sucking mosquitoes and copepods. 


\section{Conclusion}

These results evidently suggest that microsporidians have no potential as producers of microbiological preparations for controlling blood-sucking mosquitoes. However, it cannot be excluded that some species with less narrow host specificity, which have relatively recently commenced parasitizing mosquitoes, are able to influence the abundance of mosquito populations to a considerably greater degree.

\section{References}

1. Andreadis TG. Ultrastructural characterization of meiospores of six new species of Amblyospora (Microsporida: Amblyosporidae) from northern Aedes (Diptera: Culicidae) mosquitoes. J Eukaryot Microbiol. 1994;41:147-154. doi: 10.1111/j.1550-7408.1994. tb01488.x

2. Becnel JJ, Andreadis TG. Amblyospora salinaria n. sp. (Microsporidia: Amblyosporidae): parasite of Culex salinarius (Diptera: Culicidae), its life stages in an intermediate host and establishment as a new species. J Invertebr Pathol. 1998;71:258-262. doi: 10.1006/ jipa.1998.4729

3. Andreadis TG. Microsporidian parasites of mosquitoes. J Am Mosq Control Assoc. 2007;23(2 Suppl):3-29. doi: 10.2987/8756-971X(2007)23[3:MPOM]2.0.CO;2

4. Simakova AV, Vossbrinck CR, Andreadis TG. Molecular and ultrastructural characterization of Andreanna caspii n. gen., n. sp. (Microsporidia: Amblyosporidae) a parasite of Ochlerotatus caspius (Diptera: Culicidae). J Invertebr Pathol. 2008;99(3):302-311. doi: 10.1016/j.jip.2008.07.004

5. Andreadis TG, Simakova AV, Vossbrinck CF, Shepard JJ, Yurchenko YA. Ultrastructural characterization and comparative phylogenetic analysis of new microsporidia from Siberian mosquitoes: evidence for coevolution and host switching. $J$ Invertebr Pathol. 2012;109(1):59-75. doi: 10.1016/j.jip.2011.09.011

6. Andreadis TG, Takaoka H, Otsuka Y, Vossbrinck CF. Morphological and molecular characterization of a microsporidian parasite Takaokaspora nipponicus n. gen, n. sp. from the invasive rock pool mosquito, Ochlerotatus japonicus japonicus. J Invertebr Pathol. 2013;114(1):161-172. doi: 10.1016/j.jip.2013.07.007

7. Pavlovskii EN. Metody izucheniya krovososushhih komarov (Culicidae) [Methods of studying blood-sucking mosquitoes (Culcidae)]. Moscow: Nauka Publ.; 1935. 176 p. In Russian

8. Gutsevich AV, Monchadskiy AS, Shtakel'berg AA. Dvukrylye [Diptera]. In: Fauna SSSR [Fauna of the USSR]. Vol. 3, Iss. 4. Leningrad: Nauka Publ.; 1970. 184-314. In Russian

9. Vossbrinck CR, Andreadis TG, Debrunner-Vossbrinck BA. Verification of intermediate hosts in the life cycles of microsporidia by small subunit rDNA sequencing. J Eukaryot Microbiol. 1998;45(3):290-292. PMID: 9627989

10. Kukharchuk LP. Ekologiya krovososushhih komarov (Diptera: Culicidae) Sibiri [Ecology of blood-sucking mosquitoes (Diptera: Culcidae) of Siberia]. Novosibirsk: Nauka, Siberian Branch Publ.; 1981. 232 p. In Russian

11. Pestryakova TS, Korosteleva NV, Luzhkova AG. Komary severnykh rayonov Tomskoy oblasti i ikh epidemiologicheskoe znachenie [Mosquitoes of the northern districts of Tomsk oblast and their epidemiological significance]. In: Problemy kompleksnogo izucheniya geograficheskogo rayona i metodika kraev. raboty $v$ shkole: Materialy predstoyashchey nauch.-metod. konf. [Problems of a comprehensive study of the geographical area. Proc. of the Sci. Conf.]. Novokuznetsk: 1970. pp. 93-95. In Russian 
12. Pestryakova TS, Luzhkova AG. Fauna komarov Tomskoy oblasti [Fauna of mosquitoes of Tomsk oblast]. In: Trudy nauchno-issledovatel'skogo instituta biologii i biofiziki. Tomsk: Tomsk State University Publ.; 1974. Vol. 74. pp. 102-112. In Russian

13. Pestryakova TS. Komary i slepni Tomskoy oblasti (biologiya i mery bor'by) [Mosquitoes and horseflies of Tomsk oblast (biology and control measures)]. Tomsk: Tomsk State University Publ.; 1976. 22 p. In Russian

14. Luzhkova AG, Vecher LF, Mertvecova OA, Pankova TF, Fominyh VG, Franc TG. Estestvennye vragi gnusa basseyna $\mathrm{r}$. Obi [Natuaral enemies of midges of the Ob river basin]. Pestryakova TS, editor. Tomsk: Tomsk State University Publ.; 1988. 152 p. In Russian

15. Andreeva YuV, Khrabrova NV, Alekseeva SS, Sibataev AK. Species composition of mosquitoes (Diptera: Culicidae) in Tomsk region. In: Conceptual and applied aspects of invertebrate scientific research and biological education. Proc. of the IV Int. Sci. Conf. (Tomsk, Russia, October 26-28, 2015). 2015. 160-163. In Russian, English summary

16. Mirzaeva AG, Yurchenko YuA, Belevich OE. Komary [Mosquitoes]. In: Bioraznoobrazie Karasuksko-Burlinskogo rayona (Zapadnaya Sibir') [Biodiversity of Karasuk-Burlin region (Western Siberia)]. 2010:148-155. In Russian

17. Pankova TF, Issi IV, Simakova AV. New species of microsporidians Amblyospora from blood-sucking mosquitos of the family Culicidae. Parazitologiya. 2000;34(5):420-427. In Russian, English summary

18. Simakova AV, Pankova TF, Issi IV. Crepidula beklemishevi gen.et sp. $\mathrm{n}$. and Dimeiospora palustris gen.et sp. n. (Microspora: Amblyosporidae), new microsporidian species from blood-sucking mosquitoes (Diptera: Culicidae) from the south of the West Siberia. Parazitologiya. 2003;37(2):145-153. In Russian, English summary.

19. Simakova AV, Pankova TF. Microsporidia of genus Trichoctosporea (Microspora: Thelohaniidae) from blood-sucking mosquitoes (Diptera: Culicidae) of Western Siberia. Vestnik Tomskogo Gosudarstvennogo Universiteta (Prilozhenie). 2004;10:116-122. In Russian, English summary

20. Simakova AV, Pankova TF. Six new species of microsporidia of the genus Amblyospora (Microspora: Amblyosporidae) from blood sucking mosquitoes (Diptera: Culicidae) from the West Siberia. Parazitologiya. 2005;39(5):371-385. In Russian, English summary

21. Simakova AV, Lukiantsev VV, Vossbrinck CR, Andreadis TG. Identification of mosquito-parasitic microsporidia, Amblyospora rugosa and Trichoctosporea pygopellita (Microsporidia: Amblyosporidae), from Acanthocyclops venustus and Acanthocyclops reductus (Copepoda: Cyclopidae), based on small subunit rDNA analysis. Parazitologiya. 2011;45(2):140-146. In Russian, English summary

22. Andreadis TG. Life cycle, epizootiology and horizontal transmission of Amblyospora (Microspora: Amblyosporidae) in a univoltine mosquito, Aedes stimulans. J Invertebr Pathol. 1985;46(1):31-46. doi: 10.1016/0022-2011(85)90127-2

23. Sweeney AW, Hazard EI, Graham MF. Intermediate host for an Amblyospora sp. (Microspora) infecting the mosquito, Culex annulirostris. J Invertebr Pathol. 1985;46(1):98-102. PMID: 2863312

24. Andreadis TG. Comparative susceptibility of the copepod Acanthocyclops vernalis to a microsporidian parasite, Amblyospora connecticus, from the mosquito Aedes cantator. J Invertebr Pathol. 1988;52(1):73-77. doi: 10.1016/0022-2011(88)90104-8

25. Sweeney AW, Graham MF, Hazard EI. Life cycle of Amblyospora dyxenoides sp. nov. in the mosquito, Culex annulirostris and the copepod Mesocyclops albicans. J Invertebr Pathol. 1988;51(1):46-57. doi: 10.1016/0022-2011(88)90087-0

26. Becnel JJ. Horizontal transmission and subsequent development of Amblyospora californica (Microsporida: Amblyosporidae) in the intermediate and definitive hosts. Diseases of Aquatic Organisms. 1992;13:17-28. doi: 10.3354/dao013017 
27. White SE, Fukuda T, Undeen AH. Horizontal transmission of Amblyospora opacita (Microspora: Amblyosporidae) between the mosquito, Culex territans, and the copepod, Paracyclops fimbriatus chiltoni. J Invertebr Pathol. 1994;63(1):19-25. doi: 10.1006/ jipa.1994.1004

28. Micieli MV, Garcia JJ, Becnel JJ. Life cycle and description of Amblyospora camposi $\mathrm{n}$. sp. (Microsporidia: Amblyosporidae) in the mosquito Culex renatoi (Diptera: Culicidae) and the copepod Paracyclops fimbriatus fimbriatus (Copepoda: Cyclopidae). J Eukaryot Microbiol. 2000;47(6):575-580. doi: 10.1111/j.1550-7408.2000.tb00092.x

29. Micieli MV, Garcia JJ, Becnel JJ. Horizontal transmission of Amblyospora albifasciati Garcia and Becnel, 1994 (Microsporidia: Amblyosporidae) to a copepod intermediate host and the neotropical mosquito, Aedes albifasciatus (Macquart, 1837). J Invertebr Pathol. 2000;75(1):76-83. doi: 10.1006/jipa.1999.4897

30. Vossbrinck CR, Andreadis TG, Vavra J, Becnel JJ. Molecular phylogeny and evolution of mosquito parasitic Microsporidia (Microsporidia: Amblyosporidae). J Eukaryot Microbiol. 2004;51:88-95. doi: 10.1111/j.1550-7408.2004.tb00167.x

31. Andreadis TG. Evolutionary strategies and adaptations for survival between mosquitoparasitic microsporidia and their intermediate copepod hosts: a comparative examination of Amblyospora connecticus and Hyalinocysta chapmani (Microsporidia: Amblyosporidae). Folia Parasitologica. 2005;52(1-2):23-35. doi: 10.14411/fp.2005.004

32. Lukyantsev VV, Simakova AV. Infestation of lower crustaceans (Copepoda, Cladocera) with microsporidians (Microsporidia) in Western Siberia. Parazitologiya. 2014;48(5):358372. In Russian, English summary

33. Alikhanov ShG. On the infestation of natural populations of Aedes caspius caspius with microsporidians of the genus Thelohania in Azerbaijan. Parazitologiya. 1972;6(4):381384. In Russian, English summary

34. Khaliulin GL. Vliyanie sezonov goda na zabolevaemost' lichinok krovososushhih komarov mikrosporidiozom [The influence of seasons on the incidence of larvae of blood-sucking mosquitoes of microsporidiosis]. 1 Respublikanskaya nauchnaya konferenciya [The 1 Republic Sci. Conf. Thesis] (Kanev, Russia, 7-10 September 1982). Kanev; 1982. pp. 254-255. In Russian

35. Kilochitsky PYa, Georgiyeva EK. A Discovery of Cicrosporidia in Blood-Sucking Mosquitoes in Kareliya. Vestnik zoologii. 1982;5:79-80. In Russian, English summary

36. Andreadis TG. An epizootic Amblyospora sp. (Microspora: Amblyosporidae) in field populations of the mosquito, Aedes cantator. J Invertebr Pathol. 1983;42(3):427-430. PMID: 6417246

37. Khodzhaeva LF. Mikrosporidii krovososushhih dvukrylyh [Microsporidia of blood-sucking Diptera]. Gan EI, editor. In: Ekologiya parazitov zhivotnyh yugo-zapada Uzbekistana [Ecology of parasites of animals of the South-West of Uzbekistan]. Tashkent: Institute of Zoology and Parasitology of the AS of the UzSSR; 1988. pp. 81-87. In Russian

38. Andreadis TG. Epizootiology of Amblyospora connecticus (Microsporida) in field populations of the saltmarsh mosquito, Aedes cantator, and the cyclopoid copepod, Acanthocyclops vernalis. Protozoology. 1990;37:174-182. doi: 10.1111/j.1550-7408.1990.tb01123.x

39. Bykova HI. Mikrosporidii (Microsporidia) - parazity komarov (Diptera, Culicidae) Karelii [Microsporidia (Microsporidia), parasites of mosquitoes (Diptera, Culicidae) in Karelia]. In: Ekologo-populyatsionnyy analiz parazitov $i$ krovososushhih chlenistonogih [Ecologicalpopulational analysis of parasites and blood sucking arthropods]. Petrozavodsk; 1991:8193. In Russian

40. Kiloczycki PYa. Microsporidia of the blood sucking Aedes cantans mosquito group. Vestnik zoologii. 1995;2-3:3-13. In Russian, English summary

41. Kiloczicki PYa. Novye vidy mikrosporidiy krovososushhih komarov - obitateley malyh vodoemov. Gidrobiologicheskiy zhurnal - Hydrobiological Journal. 1996;32(2):83-98. In Russian, English summary 
42. Andreadis TG. Epizootiology Amblyospora stimuli (Microspora: Amblyosporidae) infections in field populations of a univoltine mosquito, Aedes stimulans (Diptera: Culicidae) inhabiting a temporary vernal pool. J Invertebr Pathol. 1999;74:198-205. doi: 10.1006/jipa.1999.4875

43. Micieli MV, Garcia JJ, Andreadis TG. Epizootiological studies of Amblyospora albifasciati (Microsporidiida: Amblyosporidae) in natural populations of Aedes albifasciatus (Diptera: Culicidae) and Mesocyclops annulatus (Copepoda: Cyclopidae) in a transient floodwater habitat. J Invertebr Pathol. 2001;77(1):68-74. doi: 10.1006/jipa.2000.4995

44. Kilochitskiy PYa. Mikrosporidii krovosisnih komariv. Kiev: Geoprint Publ.; 2002. 227 p. In Ukrainian, English summary

45. Micieli MV, Garcia JJ, Becnel JJ. Life cycle and epizootiology of Amblyospora ferocis. (Microsporidia: Amblyosporidae) in the mosquito Psorphora ferox (Diptera: Culicidae). Folia Parasitology. 2003;50:170-175. doi: 10.1006/jipa.2000.4995

46. Micieli MV, Marti GA, Garcia JJ, Tranchida MS, Becnel JJ. Epizootiological studies of Amblyospora camposi (Microsporidia: Amblyosporidae) in Culex renatoi (Diptera: Culicidae) and Paracyclops fimbriatus fimbriatus (Copepoda: Cyclopidae) in a bromeliad habitat. J Invertebr Pathol. 2006;77:68-74. doi: 10.1016/j.jip.2006.08.004

Received 11 March 2016; Revised 30 April 2016; Accepted 11 May 2016; Published 23 June 2016.

\section{Authors info:}

Simakova Anastasia V, PhD (Biol.), Ass. Professor, Department of Invertebrate Zoology, Institute of Biology, Tomsk State University, 36 Lenin Pr., Tomsk 634050, Russian Federation.

E-mail: anastasiasimakova@yahoo.com

Pankova Tamara F, Cand. Sci. (Biol.), Ass. Professor, Department of Invertebrate Zoology, Institute of Biology, Tomsk State University, 36 Lenin Pr., Tomsk 634050, Russian Federation.

E-mail: pankov44@sibmail.com

Issi Irma V, PhD (Biol.), Professor, Laboratory of Microbiological Control, All-Russian Institute of Plant Protection, 3 Podbelskogo, St. Petersburg-Pushkin 196608, Russian Federation.

E-mail: irma_issi@mail.ru

Andreeva Yülia V, Cand. Sci. (Biol.), Senior Researcher, Laboratory of Evolution Cytogenetics, Institute of Biology, Tomsk State University, 36 Lenin Pr., Tomsk 634050, Russian Federation.

E-mail: andreeva_y@mail2000.ru

Simakova AV, Pankova TF, Issi IV, Andreeva YuV. Ecological aspects of microsporidia parasitizing in natural populations of the Aedes (Diptera: Culicidae) blood-suking mosquitoes in Western Siberia. Vestnik Tomskogo gosudarstvennogo universiteta. Biologiya - Tomsk State University Journal of Biology. 2016;2(34):101-113. doi: 10.17223/19988591/34/7 